\section{Estudo \\ cobebate}

em Cestão

Plamejamento
Revista Estudo \& Debate, Lajeado, v. 27, n. 2, 2020. ISSN 1983-036X

DOI: http://dx.doi.org/10.22410/issn.1983-036X.v27i2a2020.2343

\title{
AÇÃO EXTENSIONISTA DE CUIDADO À SAÚDE: A INFLUÊNCIA NA FORMAÇÁO PROFISSIONAL DE ESTUDANTES DIPLOMADOS
}

\author{
Lidiane Musselin ${ }^{1}$, Marilucia Vieira dos Santos ${ }^{2}$, Patrícia Fassina ${ }^{3}$, \\ Fernanda Rocha da Trindade ${ }^{4}$, Paula Michele Lohmann ${ }^{5}$
}

\begin{abstract}
Resumo: A extensão universitária busca modificar as realidades, melhorando a qualidade de vida da comunidade assistida por ela, além de proporcionar novos conhecimentos para a formação dos estudantes, desde os primeiros semestres da graduação, a partir da troca de experiências entre os sujeitos envolvidos. A esse respeito, o presente estudo busca analisar o impacto na formação profissional de estudantes diplomados após sua participação no projeto de extensão "Ações Interdisciplinares de Cuidado em Saúde (PI)", vinculado à Universidade do Vale Taquari - Univates. Para isso, realizou-se uma pesquisa qualitativa com os estudantes já diplomados de cursos da área da saúde, com perguntas fechadas e abertas, para avaliação do impacto da experiência vivida no projeto durante a graduação, na vida profissional desses sujeitos. Ao final da pesquisa, foi possível perceber que a participação no projeto de extensão auxiliou os profissionais tanto no campo teórico quanto no campo prático no tocante à realizaçáo de atendimentos humanizados, multi e interdisciplinares, considerando sempre que, antes de serem profissionais de suas áreas específicas, são profissionais de saúde como um todo.
\end{abstract}

Palavras-chave: Extensão universitária. Saúde coletiva. Práticas Interdisciplinares. Formação profissional. Aprendizagem ativa.

1 Acadêmica do curso de Psicologia da Universidade do Vale do Taquari - UNIVATES/Lajeado/RS. Bolsista do Programa de Extensão Saúde e Qualidade de Vida, no Projeto Interdisciplinar de Cuidados em Saúde UNIVATES.

2 Fisioterapeuta. Mestre em ciências Biológicas: Neurociências UFRGS. Docente da Universidade do Vale do Taquari - UNIVATES.

3 Nutricionista. Mestre em Ambiente e Desenvolvimento UNIVATES. Docente da Universidade do Vale do Taquari - UNIVATES.

4 Física Médica. Mestre em Medicina: Ciências Médicas UFRGS. Docente da Universidade do Vale do Taquari - UNIVATES.

5 Enfermeira. Mestre em Ambiente e Desenvolvimento UNIVATES. Docente da Universidade do Vale do Taquari - UNIVATES. 


\title{
EXTENSIONIST ACTION FOR HEALTH CARE: THE INFLUENCE ON PROFESSIONAL TRAINING OF GRADUATED STUDENTS
}

\begin{abstract}
The university extension seeks to modify the realities and improve the quality of life of the assisted community, as well as favoring new knowledge for the formation of students, from the first semesters of the undergraduate, through the exchange of experience between the subjects involved. This study aims to analyze the impact on the professional formation of graduate students after their participation in the extension project "Interdisciplinary Health Care Actions (PI)", linked to the University of Taquari Valley - Univates. For this, a qualitative research was conducted, with closed and open questions, with the students already graduated, to evaluate the impact of the experience lived in the project during the undergraduate, in the professional life of these subjects. At the end of the research, it was possible to notice that the participation in the extension project helped the professionals, both in the theoretical and practical fields, to perform a humanized and multi and interdisciplinary care, always considering that before being professionals of the chosen areas, Health professionals.
\end{abstract}

Keywords: University Extension. Collective health. Interdisciplinary Practices. Professional qualification. Active learning.

\section{Introdução}

A universidade é um espaço potente e gerador de aprendizagens, onde se possibilita o compartilhamento do saber, considerando os elementos que regem suas atividades: ensino, pesquisa e extensão (DOS SANTOS CONDE et al., 2018). Dentre as vivências possíveis no âmbito acadêmico, encontram-se as atividades do projeto de extensão universitário, que possibilita experienciar o trabalho em equipe, articulando a teoria e a prática na atuaçáo em conjunto com a sociedade em que a academia está inserida, contribuindo para as ações de cidadania.

O Plano Nacional reafirma a extensão universitária como processo acadêmico efetivado em função das exigências da realidade, indispensável na formação do estudante, na qualificação do professor e no intercâmbio com a sociedade. Considerando que, para o exercício de cidadania profissional, é necessário a interação da universidade com a sociedade, seja para identificar as demandas socioculturais e/ou para referenciar sua formação técnica com os problemas que poderão ser encontrados em sua vida profissional (BRASIL, 2001). Assim, a ação extensionista universitária busca auxiliar na modificação da realidade e na melhora da qualidade de vida da comunidade assistida, além de favorecer a construção de novos conhecimentos a partir da troca de experiência entre os sujeitos, buscando o fortalecimento de diferentes concepçóes à respeito do trabalho profissional e social (MOURA et al., 2012).

Nesse sentido, a Universidade do Vale Taquari - Univates, situada na cidade de Lajeado, no interior do estado do Rio Grande do Sul, preocupa-se com a formação dos seus estudantes, visto que sua missão é gerar, mediar e difundir o conhecimento técnicocientífico e humanístico, considerando as especificidades e as necessidades da realidade regional, inseridas no contexto universal, com vistas à expansão contínua e equilibrada da qualidade de vida dos sujeitos. Além disso, na busca de ampliar as relaçóes entre a universidade e a comunidade com foco na discussão e na construção de propostas e de alternativas comunitárias sustentáveis orientadas à transformação da realidade social, entre 
as diversas propostas de ações acadêmicas, foi desenvolvido, em 2009, o projeto de extensão denominado "Açóes Interdisciplinares de Cuidados em Saúde (PI)", realizado em um bairro da periferia da cidade de Lajeado/RS que, segundo o IBGE (2010), encontra-se em condiçôes de vulnerabilidade socioeconômica.

As açōes do PI ocorrem semanalmente, durante todo o calendário acadêmico, promovendo a educaçáo por meio de cuidados no processo saúde-doença, sendo que todas as atividades desenvolvidas têm como ponto de partida a troca de informações com os profissionais da Estratégia de Saúde da Família (ESF), além das diversas instituiçōes de ensino e de serviço social locais. Após a identificação das demandas, as equipes multidisciplinares do PI, através de açóes interdisciplinares, buscam alternativas de açôes que contribuam para a autonomia do processo de saúde-doença das pessoas beneficiadas. Dentre os cursos de graduação envolvidos nesse projeto estão os seguintes: Enfermagem, Psicologia, Educação Física, Fisioterapia, Biomedicina, Odontologia, Estética e Cosmética, Nutrição, Jornalismo, Direito, Letras, Pedagogia, Arquitetura, Engenharia Mecânica, Engenharia de Controle e Automação, Engenharia de Produção e Administração.

Todo o trabalho desenvolvido pelo PI é realizado a partir do conceito de clínica ampliada, valorizando o conhecimento coletivo dos profissionais e das demais pessoas envolvidas, a fim de favorecer (n)a atenção integral ao sujeito (BRASIL, 2009). Também é utilizado como ferramenta pedagógica o Método do Arco Charles de Maguerez (PRADO et $a l$, 2012) para o planejamento de açóes interdisciplinares sustentáveis, que geram mudanças positivas reais na comunidade assistida.

A problematização entre professores, estudantes acadêmicos e membros da comunidade que estão inseridos no projeto de extensão contextualiza as demandas de trabalho que o estudante encontrará na sua vida profissional e no planejamento e realizaçáo das ações de cuidado em saúde, oportunizando uma formação diferenciada, que ajuda a construir um profissional crítico-reflexivo, que age de acordo com os princípios que regem o Sistema Único de Saúde (SUS), e que é capaz de transformar a realidade social do seu cotidiano, melhorando a qualidade da saúde da população (BISCARDE et al, 2014)

Nesse contexto, considerando a importância que a ação extensionista representa, no Ensino Superior, para a formaçáo acadêmica e profissional, entende-se que é de extrema importância também a constante avaliação e reavaliação de todos os processos que envolvem o trabalho, a fim de observar se o projeto está atingindo os objetivos propostos. Sendo assim, o presente estudo busca analisar o impacto na formação profissional de estudantes diplomados após sua participação no projeto de extensão "Ações Interdisciplinares de Cuidado em Saúde".

\section{Metodologia}

Para avaliar o impacto da participação de estudantes diplomados no projeto de extensão PI, foi realizado um levantamento dos acadêmicos que participaram do projeto por pelo menos um semestre ininterrupto, utilizando-se o banco de dados do próprio projeto. O período selecionado foi de 2009, quando teve início o referido projeto, até o final de 2017. 
Após esse levantamento, utilizou-se o banco de dados do setor no Núcleo de Tecnologia da Informação (NTI) da Univates para a coleta do endereço e do e-mail dos estudantes participantes durante o período supracitado. Encaminhou-se a 111 alunos, por e-mail, o link de um formulário on-line, além de uma carta de apresentação com os objetivos do estudo, sendo que o recebimento do formulário respondido foi considerado como aceite de participaçáo, dispensando-se a assinatura do Termo de Consentimento Livre Esclarecido (TCLE). A amostra final foi composta por 33 participantes, sendo 30 do sexo feminino e 3 do masculino e cuja média de idade foi de 28,7 (DP 3,4). O projeto foi previamente aprovado pelo Comitê de Ética em Pesquisa (COEP) para seres humanos (294.611/2013) da Univates.

De acordo com os procedimentos de Wachelke e colaboradores (2014), além do envio do convite e do questionário, foram feitos mais dois reenvios do mesmo e-mail, para reforçar o convite aos participantes, dentro do período de um mês, que foi o tempo proposto para a coleta de dados. O questionário foi composto por perguntas qualitativas, fechadas e abertas, sendo que, para caracterização da amostra, foram solicitadas as seguintes informaçóes: idade, sexo, curso da formação acadêmica, formaçóes posteriores, tempo de trabalho e participação em outro(s) programa(s) de extensáo universitária como voluntário. As questóes qualitativas abordaram a influência da participação do projeto de extensão PI na vida acadêmica, profissional e pessoal dos respondentes.

Para a análise dos dados, as respostas quantitativas foram descritas considerando o número total (n) e a porcentagem. Para as respostas qualitativas, foi realizada a análise de conteúdo (SANTOS, 2012) para descrição dos resultados, considerando duas categorias. A primeira foi a 'Influência das açôes extensionistas na formaçáo acadêmica', com as seguintes subcategorias: Atendimento Humanizado, Escuta Ativa, Relação entre teoriaprática, Identificando a situação-problema e Construção de projetos terapêuticos. Já a segunda categoria foi 'Contribuição da extensão universitária para a atuação profissional', da qual emergiram as subcategorias: Clínica ampliada, $\mathrm{Na}$ busca da autonomia profissional e Formação interdisciplinar. Na transcrição dos relatos, foi utilizada a sigla "E”, que significa Estudante seguido de um número inteiro para diferenciar os participantes da amostra e garantir o anonimato dos mesmos.

\section{Resultados e Discussáo}

O questionário on-line foi respondido por 33 estudantes diplomados, sendo que os respondentes eram 54,6\% do curso de Fisioterapia $(n=18)$, seguidos por $24,3 \%$ diplomados do curso de Psicologia $(n=8), 9,1 \%$ do curso de Educação Física e da Nutrição $(n=3)$ e $3 \%$ do curso de Biomedicina $(n=1)$. Destes, $48,4 \%(n=16)$ estavam cursando ou haviam concluído uma pós-graduação, $15,2 \%(\mathrm{n}=5)$ fizeram cursos técnicos de especialização na sua área de atuaçáo, 9,1\% $(\mathrm{n}=3)$ estavam realizando ou concluíram o mestrado e $6 \%(\mathrm{n}=$ 2) estavam realizando ou concluíram o doutorado.

Em relação ao tempo de atuação na área de formação, 30,3\% ( $\mathrm{n}=10)$ encontravamse entre 1 e 2 anos de atuaçáo, e 30,3\% já estavam atuando há mais de 4 anos. Outros $21,2 \%(n=7)$ estavam há menos de 1 ano, seguidos de $18,2 \%(n=6)$, entre 3 a 4 anos. 
Também, 69,7\% $(n=27)$ do total da amostra participou apenas do projeto PI, e 30,3\% $(\mathrm{n}=10)$ haviam participado também de outros projetos de extensão universitária.

\title{
1. Influência das açóes extensionistas na formação acadêmica
}

A extensão universitária é uma forma de interação que deve existir entre a universidade e a comunidade em que ela está inserida, como uma espécie de ponte permanente entre a universidade e os diversos setores da sociedade. Ela funciona como uma via de duas mãos em que a universidade contribui com conhecimentos acadêmicos e/ou assistência à comunidade e recebe dela influxos positivos em forma de retroalimentação, tais como suas reais necessidades, aspirações e conhecimento popular (NUNES; SILVA, 2011). Para os estudantes que participam do PI, é oportunizado um ambiente que proporcione vivências para o atendimento humanizado, escuta ativa, relação entre teoria da sala de aula com a prática, identificação da situação-problema e planejamento terapêutico.

\subsection{Atendimento humanizado}

O cuidar humanizado implica, por parte do cuidador, na compreensão e na valorização do ser humano enquanto sujeito histórico e social. Para isso, deve-se considerar, acima de tudo, que para desencadear um processo de humanização no ambiente de trabalho, não são necessários grandes investimentos ou adaptações no ambiente físico, mas é primordial que haja a sensibilização com relação à problematização da realidade concreta, a partir da equipe multidisciplinar (FAQUINELLO et al, 2007). Na fala dos estudantes, percebeu-se que eles reconheceram à prática do atendimento humanizado:

\footnotetext{
"Aprendi a respeitar o limite e conceitos das pessoas. Sou mais humana depois de participar do projeto, dou mais valor a vida, as pessoas e as histórias de vidas dela. Aprendi a escutar, a me relacionar com paciente e família (...)" E9
}

\begin{abstract}
"O aprendizado é ainda mais potente, não apenas como fisioterapeuta, mas como profissional da saúde, com ser humano preocupado com o cuidado de outro ser humano respeitando sua individualidade com olhar integral. Meu olhar tornou-se mais sensível e amplo, e minha prática certamente mais humana após a participação no projeto.” E15
\end{abstract}

\begin{abstract}
"A vivência me proporcionou experiência prévia com os pacientes, me ensinou como adentrar em um domicílio, além de me proporcionar o desenvolvimento interpessoal. Tudo isso me proporcionou uma formação diferenciada pautada no cuidado com o próximo, aprendendo a ver os pacientes e os familiares de uma forma integral." E16
\end{abstract}

\subsection{Escuta ativa}

A escuta ativa é um processo dinâmico, que pode ser metaforicamente comparado à leitura da mensagem contida nas entrelinhas de um texto intrincado, porque escutar é diferente de ouvir, é mais do que perceber os sons por meio da percepçáo auditiva. Tal ato configura-se como um processo emocional e cognitivo ativo e complexo que, partindo da 
percepção auditiva, considera as variáveis atenção, interesse e motivação, demandando do sujeito mais do que a simples passividade de deixar de falar, pois implica colocar atençáo no ato de ouvir, querendo compreender o outro, considerando que há um contexto significativo maior por trás das palavras pronunciadas (ARAÚJO; SILVA, 2012). A escuta ativa também foi percebida nas respostas dos diplomados:

"Passei a ver as pessoas de outra forma, percebi que tenho muito mais para ajudar do que julgar, aprimorei minha habilidade de escuta." E2

"O olhar global para/com as pessoas e o cuidado em ouvir o que a voz, o corpo e o olhar nos diz, fez com que eu perceba as pessoas de outra maneira, muito mais sensível e completa." E14

É possível perceber, diante das açóes desenvolvidas, a evolução dos usuários, partindo do propósito interdisciplinar que se sustenta em uma relação de reciprocidade e mutualidade (FAZENDA, 2002), ou seja, de interação, que facilita o diálogo entre o estudante voluntário e o beneficiário residente da comunidade atendida, assim como entre o estudante participante e o professor tutor. É a partir dessa interação que o avanço da melhoria das demandas do contexto social é perceptível. Sendo assim, o diálogo entre os usuários e o futuro profissional se torna imprescindível nas açōes realizadas dentro do PI, visto que é através da comunicação que o aluno compreende melhor as reais demandas dos usuários, o que facilita o planejamento terapêutico e preventivo a ser desenvolvido na comunidade.

\subsection{Relaçáo entre a teoria e a prática}

A teoria em si não transforma o mundo, porém, pode contribuir para sua transformaçấo, mas para isso tem que sair de si mesma e, em primeiro lugar, tem que ser assimilada pelos que vão gerar, com seus atos reais e efetivos, tal transformaçáo. A relação teoria-prática é uma dinâmica de ação-reflexão-ação, caracterizando-se esta última como uma ação transformadora, em algum grau. Nesse sentido, o percurso é percebido como uma forma de exercitar a práxis, entendida como uma prática consciente, refletida, informada e intencionalmente transformadora (BERBEL, 2011). Um dos princípios da extensão acadêmica é favorecer a articulação entre a teoria e a prática, conforme relatado pelos diplomados:

"Oportunizando me relacionar com os conteúdos estudados de forma prática. Exercita o trabalho em equipe e possibilita conhecimento sobre o contexto familiar e as patologias relacionadas." E6

"Esse projeto difere de qualquer outra prática que tive acesso durante o meu período de formação, pois ele aborda não só a especificidade da sua formação, mas a interdisciplinaridade, a assistência a saúde pública e etc.” E8 
"O projeto teve grande influência na escolha do tema de meu trabalho de conclusão, bem como a escolha profissional.” E2

A extensão também ocupa lugar tão importante quanto o ensino e a pesquisa, pois é, sobretudo, por meio dela que os dados empíricos imediatos e teóricos se confrontam, gerando as permanentes reelaboraçóes que caracterizam a construção do conhecimento científico (DOS SANTOS, 2012).

\subsection{Identificando a situaçáo-problema}

O estudante, ao estabelecer contato com o território adscrito à unidade do bairro onde são desenvolvidas as atividades do projeto, precisa reconhecer a promoção da saúde, antes mesmo de pensar em análise do contexto dos indivíduos que fazem parte dos atendimentos. No Brasil, a promoção da saúde, diga-se de passagem, é recente e em expansão, porém com enorme potencial, dadas as demandas emergentes na década de 90 (de acordo com a Constituição de 1988), em que é favorecida a descentralização e o fortalecimento da participação popular e o controle social da população nas questōes de saúde (WESTPHAL, 1998).

Tendo isso como pressuposto, afirma-se que o SUS é uma política pública que tem como princípios, além do direito à saúde, a participação da população na gestão dos serviços, a integralidade e a equidade das açóes (MATTOS, 2009). Nesse viés, os estudantes necessitam de conhecimento não apenas sobre o tratamento das doenças, mas um saber centrado em modelos de atenção e voltado para os determinantes das condiçóes de saúde de uma população.

A esse respeito, os estudantes diplomados afirmaram que tiveram a oportunidade de identificar situaçóes-problema no momento de seus atendimentos e articular a tomada de decisão, juntamente com sua equipe multidisciplinar, bem como com os profissionais da unidade de saúde.

"Foi possível conviver com a realidade de muitas famílias, suas necessidades e poder desenvolver estratégias de cuidado para estes usuários.” E4

\footnotetext{
"Oportunizando me relacionar com os conteúdos estudados de forma prática. Exercita o trabalho em equipe e possibilita conhecimento sobre o contexto familiar e as patologias relacionadas." E6
}

\subsection{Construçáo de projetos terapêuticos}

Pensando no contexto interdisciplinar do projeto desenvolvido, incorpora-se a utilização do projeto terapêutico singular (PTS) com açóes que recolhem a contribuiçáo de várias especialidades e de distintas profissóes. Nesse contexto, para analisar as condiçóes de saúde da população é necessária uma avaliação compartilhada sobre as condições do usuário, sendo também acordados procedimentos, que ficam a cargo de diversos membros 
da equipe multiprofissional, denominada equipe de referência (CAMPOS; DOMITTI, 2007, CAMPOS; AMARAL, 2007).

A construção dos projetos é realizada através da tutoria com um professor da equipe, com a participação e concordância da unidade de saúde do território. As atividades têm o seu início no momento em que os estudantes realizam a visita domiciliar ou nas instituiçóes e tais açôes têm sequência durante todo o semestre, pois não se esgotam, uma vez que há a necessidade de constante avaliação e discussão com o usuário e com a equipe que o atende. Desse modo, o estudante diplomado define os atendimentos e o PTS, como:

\footnotetext{
"Enfrentar desafios com a orientação dos professores, discutir os casos e principalmente, olhar os atendimentos de forma interdisciplinar. Este último quesito, a mim foi fundamental, pois ficamos olhando uma atuação em saúde quase sempre sob um ponto de vista. Olhar o sujeito como um todo, sobre mais de um aspecto." E17
}

Entende-se também que para elaboração do PTS é necessário levar em conta a opiniáo, sonhos, anseios e o projeto de vida dos usuários assistidos. O projeto é singular e coletivo, através de uma interação democrática e horizontal entre o terapeuta - usuário - família. Comprometer-se com o ato de cuidar e orientar para o cuidado em saúde é o desafio de ir além dos discursos e lançar mão das práticas transformadoras do modelo assistencial (PINTO et.al, 2011).

\section{Contribuiçóes da extensão universitária para a atuação profissional}

A extensão universitária caracteriza-se como um meio facilitador para a articulação entre o estudante e a comunidade, possibilitando o confron to do acadêmico com a realidade da população (PEREIRA et al, 2011). Nesse sentido, a atividade dos estudantes nas comunidades beneficia a formação deles enquanto profissionais , pois favorece o trabalho com as pessoas de forma a permitir uma ação mais humanista e integrada, sendo que essa experiência produz não só o conhecimento das pessoas, dos problemas e do sistema social em que estão inseridos, mas também dos laços de confiança, familiaridade, sensibilidade social, cultural e consciência política, aspectos essenciais para o êxito de uma intervenção (DICKSON; ABEGG, 2000).

A interação ensino-comunidade favorece a construção de novos conhecimentos no entendimento geral do processo saúde-doença, além daqueles trabalhados na sala de aula, possibilitando a formação de um profissional com visão mais ampliada de mundo (MENDES et al, 2005). Assim, as atividades de extensão estão diretamente relacionadas ao aprendizado quanto ao número de pessoas atendidas e à satisfação pessoal do acadêmico (FRANK, 2002). Por isso, o serviço comunitário tem grande importância na motivação e no incentivo do estudante acadêmico dentro de sua carreira profissional (PEREIRA et al, 2011).

\subsection{Clínica ampliada}

A clínica ampliada consiste na compreensão do processo saúde-doença e na inclusão dos usuários como cidadãos participantes das condutas em saúde, inclusive da elaboração 
de seu projeto terapêutico por meio da articulação de diferentes saberes. Assim, a clínica ampliada busca integrar abordagens em diferentes instâncias, como patologias orgânicas, aspectos econômicos, culturais e étnicos, situaçóes afetivas, entre outros, sendo cada uma delas mais ou menos relevante em cada momento, a fim de possibilitar um manejo eficaz da complexidade do trabalho em saúde, que é transdisciplinar e multiprofissional.

Trata-se, então, de criar um contexto favorável para permitir a discussão de atividades que não sejam restritas somente à doença do indivíduo ou ao núcleo profissional (BRASIL, 2009). Esse conceito de clínica ampliada, vai ao encontro das abordagens realizadas pelos diplomados do presente estudo, sendo as seguintes:

\footnotetext{
"Hoje, na minha prática, consigo ter uma visão além do paciente, do que ele me traz nos atendimentos. É possível ter a noção de ambiente de vida, de necessidades e como atuar perante esses entraves." E4
}

\begin{abstract}
"Esse projeto em si, nos oportunizou conviver com os pacientes e seus familiares, na sua residência; conhecer sua rotina e sua realidade, o que me fez despertar para o quanto isso que é algo táo subjetivo, e muitas vezes ignorado. De fato, importa no resultado do tratamento em si. Hoje em dia eu atento para esses detalhes, nos meus atendimentos." E9
\end{abstract}

\begin{abstract}
"Me ensinou a trabalhar na área da saúde analisando e dando valor a outras possibilidades e estratégia de cuidado, ou seja, para além da minha opinião formada enquanto profissional psicóloga.” E26
\end{abstract}

\title{
2.2 $\mathrm{Na}$ busca da autonomia profissional
}

A autonomia profissional pode ser definida como a forma de se governar, a liberdade ou independência moral/intelectual ou ainda a propriedade pela qual o homem pretende poder escolher as leis que regem sua conduta (FERREIRA, 1986) com a finalidade de usufruir da capacidade de governar-se pelos próprios meios e tomar decisōes livremente (DOS SANTOS et al, 2017). Portanto, pressupóe competência e liberdade para se proceder às escolhas conscientes, dentro das opçôes possíveis (BERTI et al, 2008), o que pode ser percebido no relato dos estudantes diplomados:

"Me senti mais preparada e confiante para os atendimentos logo após estar formada." E20

"Proporcionando uma maior familiarização com o planejamento e realização de ações sociais dentro da empresa em que atuo." E27

A autonomia está embasada na direção da vontade do indivíduo para a ação, a partir de influências sociais e culturais (MORIN, 2001), sendo o conhecimento científico e a construção e explicitação de um saber específico constituintes dos alicerces da autonomia profissional. Esse contexto está reforçado na abordagem do estudante diplomado E1: 
"Possibilitou maior correlação da teoria e prática, construção de consciência crítica diante das abordagens em saúde, instigando a busca por conhecimento." E1

Para o estabelecimento da autonomia profissional deve-se considerar, além dos aspectos profissionais e técnicos, os sentimentos e atitudes humanas, como a solidariedade, a empatia, a ética, a responsabilidade, além da negociação política e da postura crítica (GOMES, 2002). Ao mesmo tempo, comportamentos pessoais eticamente orientados e profissionalmente comprometidos com a saúde da população (GOMES; OLIVEIRA, 2005). O mesmo foi observado no relato de um estudante diplomado E16:

\begin{abstract}
"Hoje trabalho na saúde pública e privada, a maioria dos atendimentos que realizo em ambos é domiciliar, esse contato no bairro me preparou para o mercado de trabalho. Participar da rotina de uma família foi fundamental para me sentir segura na atuaçáo profissional, o contato com outros profissionais também contribui para uma maior facilidade no encaminhamento de pacientes." E16
\end{abstract}

\title{
2.3 Formaçáo interdisciplinar
}

O prefixo 'inter', tem o significado de troca, reciprocidade e 'disciplina', de ensino, instrução, ciência. Logo, a interdisciplinaridade pode ser compreendida como sendo a troca de reciprocidade entre as disciplinas ou ciências, ou melhor, áreas do conhecimento (FAZENDA, 2001).

A inserção das atividades de extensão universitária no serviço de saúde possibilita a interação entre os cursos de graduação e a rede pública de saúde. A realização das ações, de forma integrada, proporciona aos profissionais e aos estudantes a discussão dos conhecimentos, articulando os diferentes saberes da teoria e da prática, contribuindo para que o profissional da saúde esteja preparado para trabalhar de forma multi e interdisciplinar (BICALHO et $a l, 2018)$. Para uma atuação interdisciplinar, se faz necessário que o profissional adquira competências para atender as intervençóes solicitadas através da conjunçấo de diferentes saberes disciplinares, interagindo dinamicamente e sem hierarquização que subjugue os demais profissionais participantes. Da mesma forma, os estudantes diplomados também destacam esses ganhos com a experiência adquirida após terem participado do projeto PI:

\footnotetext{
"Busco também atuar de forma interdisciplinar, realizando diálogos constantes com os demais colegas e planejando junto com estas ações de cuidado. Me auxiliou a compreender que para trabalhar em equipe preciso respeitar o espaço do outro, compreendendo que nem sempre teremos a mesma opiniāo e que somente o diálogo possibilitará resolvermos as diferenças." E29
}

"O projeto ensinou e nos fez praticar as interaçóes com demais cursos da saúde." E9

\footnotetext{
"Trabalhei por algum tempo com uma equipe interdisciplinar, onde a forma de atender o paciente era a mesma." E24
} 
É importante também destacar que, para que um trabalho em equipe seja efetivo no desenvolvimento das açóes interdisciplinares, é necessário que o profissional seja capaz de ouvir e falar, de modo que o diálogo possa ser construtivo, dando oportunidade para que todos envolvidos exponham sua opinião e seu conhecimento técnico. Dessa forma, possibilita-se um trabalho coletivo no planejamento de estratégias resolutivas para as demandas sociais encontradas.

\footnotetext{
"Aprendi a ouvir e refletir sobre as opiniōes dos outros profissionais. O saber deve ser compartilhado para assim disseminar a saúde como um todo." E30
}

"A gente aprende a se relacionar em equipe e a necessidade de cuidado do outro." E18

\section{Conclusáo}

Aprender a trabalhar interdisciplinarmente, desde a formação acadêmica, é uma necessidade real e atual, para que o profissional possa estar apto a atuar frente à complexidade da vida social. Mesmo porque um dos desafios encontrados na rede de atenção básica da saúde é ter profissionais que estejam dispostos a discutir os casos clínicos dos usuários de forma aberta e coletiva .

Nesse contexto, o projeto extensionista PI auxilia na formação acadêmica e profissional diferenciada, capacitando o estudante para atender as demandas sociais vigentes no exercício da cidadania. Além disso, para os estudantes diplomados que participaram do PI, a experiência no projeto lhes proporcionou conhecimento teórico e prático em relação ao atendimento humanizado, estratégias terapêuticas para atendimento integral aos sujeitos assistidos e formas de trabalho multi e interdisciplinar.

\section{Referências}

ARAÚJO, Monica Martins Trovo de et al. O conhecimento de estratégias de comunicação no atendimento à dimensão emocional em cuidados paliativos. Texto $\&$ Contexto-

Enfermagem, v. 21, n. 1, p. 121-129, 2012.

BERBEL, Neusi Aparecida Navas. As metodologias ativas e a promoçăo da autonomia de estudantes. Semina: Ciências Sociais e Humanas, v. 32, n. 1, p. 25-40, 2011.

BERTI, H. W. et al. Percepção de enfermeiros recém-graduados sobre sua autonomia profissional e sobre o processo de tomada de decisão do paciente. Rev Latino-am Enfermagem, v. 16, n. 2, p. 184-91, 2008.

BICALHO, Maria Gabriela Gabriela Parenti et al. Projetos interdisciplinares de extensão universitária: possibilidades formativas no campo da saúde. CAMINHO ABERTO: REVISTA DE EXTENSÃO DO IFSC, 2018. 
BISCARDE, Daniela Gomes dos Santos; PEREIRA-SANTOS, Marcos; SILVA, Lília Bittencourt. Formação em saúde, extensão universitária e Sistema Único de Saúde (SUS): conexões necessárias entre conhecimento e intervenção centradas na realidade e repercussões no processo formativo. Interface-Comunicação, Saúde, Educação, v. 18, p. 177-186, 2014.

BRASIL. Fórum de Pró-Reitores de Extensão das Universidades Públicas Brasileiras e pela Secretaria de Educação Superior do Ministério da Educação e do Desporto. Plano Nacional de Extensão Universitária. 2001.

BRASIL. Ministério da Saúde. Secretaria de Atenção à Saúde. Política Nacional de Humanização da Atenção e Gestão do SUS. Clínica ampliada e compartilhada. Ministério da Saúde, Secretaria de Atenção à Saúde, Política Nacional de Humanização da Atenção e Gestão do SUS. - Brasília : Ministério da Saúde, 2009. 64 p.

CAIRES, Carla Maria; SILVA, Maria de Fátima Gomes dos S.; LOPES, Roberta Adyr. A importância das atividades de extensáo na formaçáo acadêmica: A experiência do projeto universidade solidária. Instituição UNINOVE.

CAMPOS, Gastão Wagner de Sousa; DOMITTI, Ana Carla. Apoio matricial e equipe de referência: uma metodologia para gestão do trabalho interdisciplinar em saúde. Cadernos de saúde pública, v. 23, p. 399-407, 2007.

CAMPOS, Gastão W. S.; AMARAL, Márcia A. A clínica ampliada e compartilhada, a gestão democrática e redes de atenção como referenciais teórico-operacionais para a reforma do hospital. Ciênc. saúde coletiva, v. 12, n. 4, 2007.

CARNIEL, Raquel K. et al. A Clínica Ampliada como ferramenta de cuidado e ensino em Geriatria. Revista da ABENO, v. 17, n. 4, p. 99-107, 2017.

MATTOS, Ruben Araujo de. Princípios do Sistema Único de Saúde (SUS) e a humanização das práticas de saúde. Interface-Comunicação, Saúde, Educação, v. 13, p. 771-780, 2009.

DICKSON, M.; ABEGG, C. Desafios e oportunidades para a promoção de saúde. In: Buischi YP. Promoção de saúde Bucal na clínica odontológica, série EAP-APCD. São Paulo: Artes Médicas; 2000.

DOS SANTOS, Érick I. et al. Facilidades e Dificuldades à Autonomia Profissional de Enfermeiros no Cuidado de Pessoas com Feridas: Estudo de Representaçóes Sociais. Estima v. 15, n. 1, p. 3-9, 2017.

DOS SANTOS, Marcos Pereira. Contributos da extensão universitária brasileira à formação acadêmica docente e discente no século XXI: um debate necessário. Revista Conexáo UEPG, v. 6, n. 1, p. 10-15, 2012. 
DOS SANTOS CONDE, Ananda et al. O Projeto Rondon e a integração entre aprendizagem e interdisciplinaridade: Operação Itacaiúnas e ampliação do conhecimento entre estudantes de medicina e enfermagem. Revista Diálogos, v. 21, n. 2, 2018.

FAQUINELLO, Paula; HARUMI HIGARASHI, Ieda; SILVA MARCON, Sonia. O atendimento humanizado em unidade pediátrica: percepção do acompanhante da criança hospitalizada. Texto \& Contexto Enfermagem, v. 16, n. 4, 2007.

FAZENDA, Ivani Catarina Arantes. Interdisciplinaridade: um projeto em parceria. Edições Loyola, 2002.

FERREIRA, A. B. H. Novo dicionário da língua portuguesa. Rio de Janeiro: Nova Fronteira; 1986.

FRANK, M. C. Providing volunteer dentistry in a foreign country. Tex Dent J. v. 119, p. 1130-1, 2002.

GOMES, A. M. T. A autonomia profissional da enfermagem em saúde pública: um estudo de representaçóes sociais. [dissertação] Rio de Janeiro (RJ): Faculdade de Enfermagem da UERJ; 2002.

GOMES, Antonio M. T.; OLIVEIRA, Denize C. Estudo da estrutura da representação social da autonomia profissional em enfermagem. Rev Esc Enferm USP, v. 39, n. 2, p. $145-53,2005$.

IBGE - Instituto Brasileiro de Geografia e Estatística. Censo 2010. Rio de Janeiro, 2010.

MENDES, R. F. et al. Contribuição do estágio supervisionado da UFPI para a formação humanística, social e integrada. Rev ABENO, v. 6, p. 61-5, 2005.

MORIN, E. A cabeça bem feita: repensar a reforma, reformar o pensamento. Tradução de E. Jacobina. 3a ed. Rio de Janeiro (RJ): Bertrand Brasil; 2001.

MOURA, Lúcia de Fátima Almeida de Deus et al . Impacto de um projeto de extensão universitária na formação profissional de egressos de uma universidade pública. Rev.

odontol. UNESP, Araraquara , v. 41, n. 5, p. 348-352, Oct. 2012

NUNES, Ana Lucia de Paula Ferreira; DA CRUZ SILVA, Maria Batista. A extensão universitária no ensino superior e a sociedade. Mal-Estar e Sociedade, v. 4, n. 7, p. 119133, 2011.

PINTO, Diego Muniz et al. Projeto terapêutico singular na produção do cuidado integral: uma construção coletiva. Texto and Contexto Enfermagem, v. 20, n. 3, p. 293, 2011.

PEREIRA, Stela Márcia et al . Extensão universitária e trabalho voluntário na formação do acadêmico em Odontologia. Arq. Odontol., Belo Horizonte , v. 47, n. 2, jun. 2011 . 
PRADO, Marta Lenise do et al. Arco de Charles Maguerez: refletindo estratégias de metodologia ativa na formação de profissionais de saúde. Esc. Anna Nery Rev. Enferm, v. 16, n. 1, p. 172-177, 2012.

SANTOS, Fernanda Marsaro dos. Análise de conteúdo: a visão de Laurence Bardin. 2012.

WACHELKE, João et al . Caracterização e Avaliação de um Procedimento de Coleta de Dados Online (CORP). Aval. psicol., Itatiba , v. 13, n. 1, p. 143-146, abr. 2014.

WESTPHAL, M. F.; ZIGLIO, E. A promoção a saúde no Brasil. Sáo Paulo: Faculdade de Saúde Pública/USP, 1998. 